\title{
Effect of composition on physical properties of food powders**
}

\author{
Karolina Szulc* and Andrzej Lenart \\ Department of Food Engineering and Process Management, Warsaw University of Life Sciences, \\ Nowoursynowska 159c, 02-776 Warsaw, Poland
}

Received March 16, 2015; accepted February 22, 2016

\begin{abstract}
A bstract. The paper presents an influence of raw material composition and technological process applied on selected physical properties of food powders. Powdered multi-component nutrients were subjected to the process of mixing, agglomeration, coating, and drying. Wetting liquids ie water and a $15 \%$ water lactose solution, were used in agglomeration and coating. The analyzed food powders were characterized by differentiated physical properties, including especially: particle size, bulk density, wettability, and dispersibility. The raw material composition of the studied nutrients exerted a statistically significant influence on their physical properties. Agglomeration as well as coating of food powders caused a significant increase in particle size, decreased bulk density, increased apparent density and porosity, and deterioration in flowability in comparison with non-agglomerated nutrients.
\end{abstract}

Ke y w ords : food powders, physical properties, rice starch, agglomeration, coating

\section{INTRODUCTION}

Application of suitable technological treatments ie agglomeration or coating, allows obtaining numerous profitable features of products from the point of view of food quality and safety, including especially stability during processing and storage (Dacanal and Menegalli, 2010; Sharma et al., 2013). Dairy-based powders constitute a large part of instant powders used in the food industry. They have to follow strict specifications of safety, nutrition, and physicochemical stability. In some cases, the nutritional profile needs to be balanced through the addition or replacement of specific components, for example carbohydrates. However, the powder should keep its functionalities regardless of its

*Corresponding author e-mail: karolina_szulc@sggw.pl

**This work was supported by Iuventus Plus project No. IP2010 0416 70, Ministry of Science and Higher Education (2010-2011). changed composition. Consumers expect that the powder reconstitution properties remain convenient and fast, as it would for a powder (Montes et al., 2011).

Agglomeration of food powders is successfully used in order to improve the instant properties of spray-dried products. The process is called 'instantization' and is applied in manufacturing of milk products (hot chocolate, instant milk), drinks (tea, coffee) or products based on starch (soups, sauces, dinner concentrates, baby food powders) (Vissotto et al., 2010). It is also applied for improvement of transport properties of the material (flowability), or improvement in product attractiveness in terms of both its visual features and sensorial properties, and a decrease in its density, as well as prevention of caking during the storage. Such physical properties of agglomerated products as particle size, porosity, solubility, wettability, shape, and bulk density depend on the type of agglomeration and process parameters applied (Barkouti et al., 2013). Agglomeration in the fluidized bed is suitable for obtaining products in a form of agglomerate with high porosity and good mechanical strength significant in further processes connected with their turnover (Dacanal and Menegalli, 2010; Jianpong et al., 2008; Szulc and Lenart, 2010; Vissotto et al., 2010).

The fluid bed technology can be used to coat particles by spraying them with a coating solution of any desired material. When the spray nozzle is placed at the bottom (with addition of a cylindrical central tube), the coating material raises the particles, preventing premature drying of the solution before reaching and coating the particles (Prata et al., 2012). Additionally, food powder coating allows controlled release of labile nutrients as well as

(C) 2016 Institute of Agrophysics, Polish Academy of Sciences 
volatile and flavour-aroma compounds and protection thereof against external factors (Chen et al., 2009; Karlsson et al., 2011).

The aim of the study was to assess the influence of raw material composition, agglomeration, and coating on selected physical properties of food powders.

\section{MATERIALS AND METHODS}

The raw material included lactose (L), whey protein isolate (WPI), soy protein isolate (SPI), rice starch (RS), wheat starch (WS), inulin (I), and vitamin C (C). Food powders were mixed to obtain a protein-carbohydrate nutrient with a composition similar to milky rice or wheat porridge (baby foods) available on the Polish market. The basic composition of the powdered multi-component nutrients (nutrients) included:

1. L $60 \%+$ WPI $25 \%+$ RS $13 \%+$ I $1.9 \%+$ C $0.1 \%$,

2. L $60 \%+$ WPI $25 \%+$ WS $13 \%+$ I $1.9 \%+$ C $0.1 \%$,

3. L $60 \%+$ SPI $25 \%+$ RS $13 \%+$ I $1.9 \%+$ C $0.1 \%$.

Technological methods included four processes: mixing, agglomeration, coating, and drying. Mixing of a given material was performed in a laboratory mixer for loose material granulation Lödige type L5 (Lödige Ploughshare Mixer). Agglomeration, coating, and drying were conducted in one apparatus, in laboratory agglomerator STREA 1 with the possibility of coating the material (Niro-Aeromatic $\mathrm{AG})$. Water and a $15 \%$ water lactose solution were used as the wetting liquids in agglomeration and the $15 \%$ water lactose solution was applied in coating processes.

Water content of equilibrated samples was measured by the vacuum-drying method $\left(70^{\circ} \mathrm{C}, 10 \mathrm{kPa}, 24 \mathrm{~h}\right)$.

Water activity was measured using a Rotronic model Hygroskop DT 1 (Domian and Poszytek, 2005).

Particle size distribution was measured in air with a Kamika particle size analyzer (Kamika Instruments, Poland) with a powder feeder unit. The analyser uses a method based on measurement of changes in the infrared radiation beam dispersed by particles moving within the measurement zone (Szulc and Lenart, 2013).

Loose and tapped bulk density were measured using a volume presser (J. Engelsmann A.G.), where the volume of a given mass of powder after 100 taps was measured to calculate the tapped bulk density (Fitzpatrick et al., 2004; Szulc and Lenart, 2010).

The Hausner ratio and the Carr index were calculated as a relationship between the tapped and the loose bulk density of the powder (Jinapong et al., 2008; Turchiuli et al., 2005).

Apparent density was measured using a gas stereopycnometer (Quantachrome Instruments). A sample was placed in the sample cell and degassed by purging with a flow of dry gas (helium) by a series of pressurization cycles (Szulc and Lenart, 2013).
Porosity of the sample $(\varepsilon)$ was calculated using the relationship between the tapped bulk density $\left(\rho_{\mathrm{T}}\right)$ and apparent density of the powder ( $\rho$ ) (Eq. (1)) (Szulc and Lenart, 2013):

$$
\varepsilon=\frac{\rho-\rho_{T}}{\rho} 100 .
$$

Wettability of the powder was determined with an A/S Niro Atomizer (1978). $100 \mathrm{ml}$ of distilled water (at $\left.21^{\circ} \mathrm{C}\right)$ was poured into a beaker. A powder sample $(10 \mathrm{~g})$ was placed around the pestle (inside the funnel so that it blocked the lower opening), the pestle was lifted, and the stopwatch was started at the same time. Finally, time was recorded when the powder became completely wetted (visually assessed as the time when all the powder particles penetrated the surface of the water).

Dispersibility was determined according to Shittu and Lawal (2007). Dispersibility of the powder was determined by dissolving approximately $10 \mathrm{~g}$ of each sample in $100 \mathrm{ml}$ of distilled water at $21^{\circ} \mathrm{C}$. The nutrient was manually stirred for $1 \mathrm{~min}$ and then left for $30 \mathrm{~min}$ to settle down the suspended particles before the supernatant was carefully decanted. The mass of the supernatant was then determined by transferring an aliquot of the supernatant into a $50 \mathrm{ml}$ density bottle. The weight of the dispersed solid was calculated as double of the difference in the mass of the supernatant and an equal volume $(50 \mathrm{ml})$ of distilled water. All the weight determinations were done in duplicate using digital scales.

The colour of the powders was determined using a Minolta chromameter (model CR-300, Minolta Co.) equipped with an adaptor for granulated and powdered materials (CR- A50). The colour parameters were measured using a CIELAB system $\left(L^{*}, a^{*}, b^{*}\right)$ and expressed in accordance with Horváth and Hodúr, 2007; Manickavasagan et al., 2015; Telis and Martinez-Navarrete, 2010. In this coordinate system, the $\mathrm{L}^{*}$ value is a measure of lightness (contribution of black or white varying between 0 and $100)$; the $\mathrm{a}^{*}$ value is used to denote redness $(+)$ and greenness $(-)$, and the $b^{*}$ value is used to denote yellowness $(+)$ and blueness (-). The studied food powders were analyzed using differential scanning calorimeter (DSC) Q200 (TA Instruments). The calorimeter was calibrated by verification of standard melting and enthalpy temperatures using high purity indium and sapphire. All the measurements were performed in a nitrogen atmosphere as a cooling medium. Before the specific calorimetric measurement, the samples of the material were dried in a vacuum drier under lowered pressure $(10 \mathrm{kPa})$ at a temperature of $70^{\circ} \mathrm{C}$ for $24 \mathrm{~h}$, and prior to the analysis they were stored in an environment of water activity close to zero $\left(\mathrm{CaCl}_{2}\right)$. The reference sample was an empty aluminium container closed in a nonhermetical manner. The mass of the powder was 11-13 mg; the samples were cooled up to a temperature of $-60^{\circ} \mathrm{C}$ and maintained at that temperature for $5 \mathrm{~min}$. The thermogram of the powder was obtained as a result of sample heating 
from a temperature of -60 to $250^{\circ} \mathrm{C}$ with a rate of $5^{\circ} \mathrm{C} \mathrm{min}^{-1}$. Thermograms presenting heat flow absorbed or released by the material sample $\left(\mathrm{W} \mathrm{g}^{-1}\right)$ depending on the temperature $\left({ }^{\circ} \mathrm{C}\right)$ were obtained during the study.

All technological trials and measurements were performed at least two times. One-way analysis of variance (ANOVA) was carried out using Statgraphics Plus 4.1 software. Statistical differences between means were determined using the LSD test at a $95 \%$ confidence level $(\alpha=0.05)$.

\section{RESULTS AND DISCUSSION}

The analyzed food powders (nutrients) were characterized by considerable differentiation in terms of water content and water activity (Fig. 1a, b); however, the water content in the studied nutrients did not exceed $6 \mathrm{~g} \mathrm{H}_{2} \mathrm{O} 100 \mathrm{~g}$ d.m. ${ }^{-1}$ and the water activity was lower than 0.35 .

The type of starch used (rice or wheat) significantly influenced the diameter of the particle size of the multicomponent nutriens obtained (Fig. 1c). Agglomeration of food powders also caused a significant $(\alpha=0.05)$ increase in the particle size. This was also confirmed in the study conducted by Jinapong et al. (2008), Machado et al. (2014); or Szulc and Lenart (2010). The raw material composition of the nutrient exerted a significant influence on the size of particles obtained in the form of agglomerate, while the type of the wetting liquid (water or $15 \%$ water lactose solution) had a lesser effect. The particle size values for the nutrients ranged from 114 to $151 \mu \mathrm{m}$, for agglomerates obtained using water as the wetting liquid from 170 to $262 \mu \mathrm{m}$, and for agglomerates obtained using the $15 \%$ water lactose solution from 170 to $250 \mu \mathrm{m}$. The agglomerates in which rice starch was substituted by wheat starch (nutrient 2) were characterized by the highest increase in particle size, irrespective of the type of the wetting liquid (Szulc and Lenart, 2012). The coating of agglomerated nutrient 1 contributed to a further statistically significant increase in particle size, with respect to the material before and after the agglomeration process. It was noted that, except the coating, concurrent additional agglomeration of the studied material also occurred (nutrient 1). The type of the liquid wetting the agglomerated material also significantly influenced the median. This relationship was also observed by Szulc and Lenart (2012).

The raw material composition of the nutrients $(1,2$, and 3) statistically significantly influenced the loose and tapped bulk density of the studied powdered nutrients (Fig. 2a, b). A statistically significant decrease in bulk density of the agglomerates obtained was observed, depending on the raw material composition of the nutrient and the type of the wetting liquid. The coating of nutrient 1 caused a statistically significant increase in loose and tapped bulk density, compared to the nutrient in the form of agglomerate. A statistically significant decline in bulk density

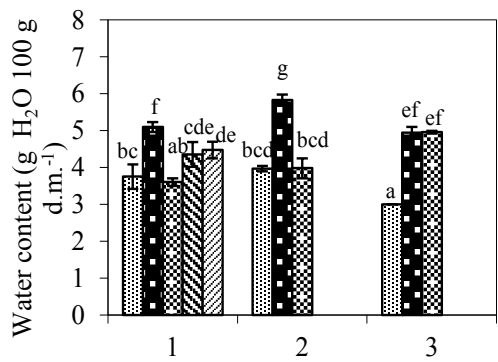

$\mathrm{b}$
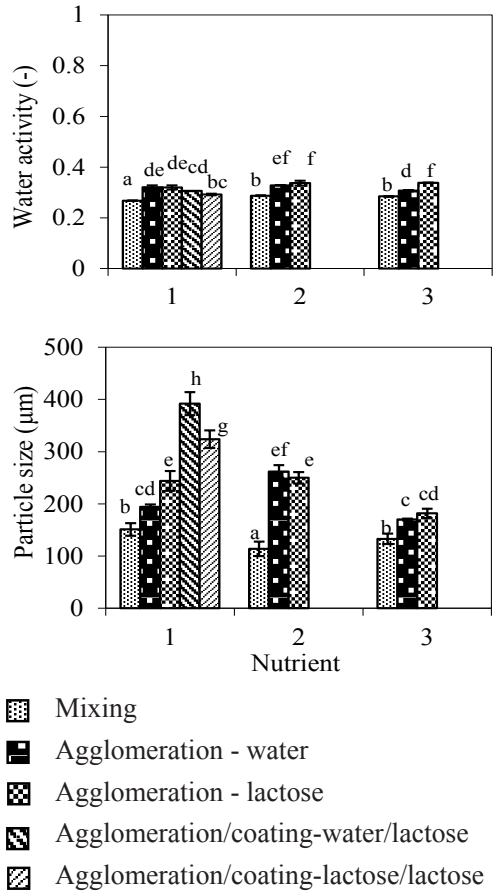

Fig. 1. Physical properties of food powders (nutrients): a - water content, $\mathrm{b}$ - water activity, $\mathrm{c}-$ particle size (median). Values followed by a different letter are significantly different at $p<0.05$.

of coated nutrient 1 , compared to an initial material, was observed only for the coating with application of water as the wetting liquid. The Hauser ratio and the Carr index determine the flowability of the studied powdered material. Multi-component nutrients and coated agglomerates may be classified as a material with a very good flowability, as indicated by the calculated Hausner ratio value below 1.2 and the Carr index below 18\% (Fig. 2c, d). In turn, the agglomerates obtained may be classified as material with fair flowability (Hausner ratio 1.2-1.4 and Carr index 18-25\%). In the study by Szulc et al. (2012), agglomeration of commercial nutrients with water led to improvement of the flowability of the agglomerates obtained according to the Hausner ratio and the Carr index. Statistical analysis of the values of the Hausner ratio and the Carr index confirmed a similar tendency in determination of the flowability of particular nutrients in the form of powder, agglomerate, and coated agglomerate. Based on the conducted statistical analysis, no significant influence of the raw material composition of the nutrient on the values of the Hausner ratio 


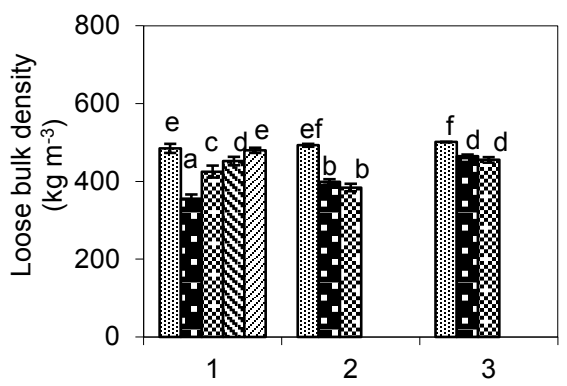

b

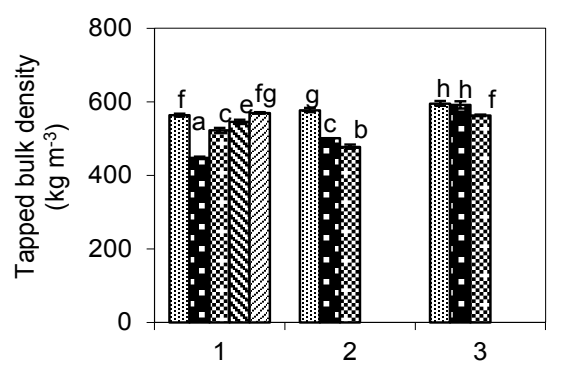

c

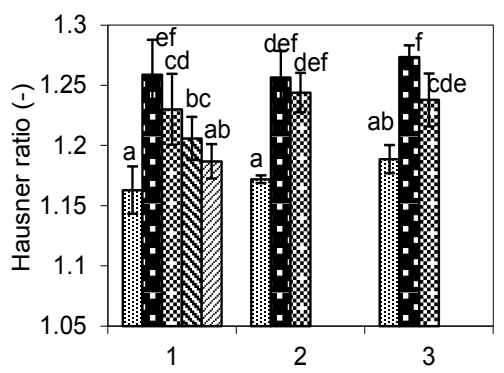

d

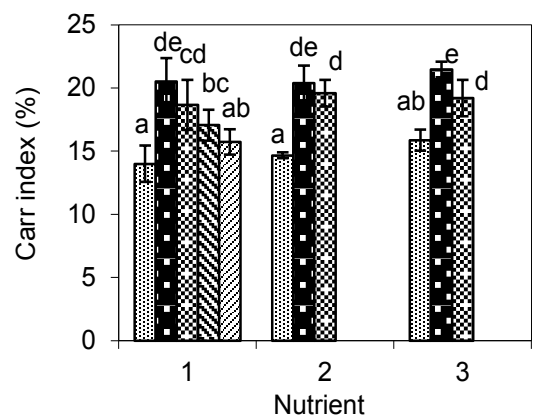

Fig. 2. Physical properties of food powders (nutrients): a - loose bulk density, b - tapped bulk density, c - Hausner ratio, $\mathrm{d}-$ Carr index. Legend and explanations as on Fig. 1.

and the Carr index was observed (Fig. 2c, d). Statistically significant deterioration of the flowability of the analyzed material (increase in the Hauser ratio and the Carr index) was noted during the process of agglomeration of the examined nutrients. The coating of agglomerated nutrient 1 caused improvement in flowability, compared to the agglomerated material (Fig. 2c, d). The technological process significantly influenced the flowability of the studied nutrients. The agglomeration caused a significant reduction of flowability determined based on the Hausner ratio (from 1.16-1.19 to 1.23-1.27) and the Carr index (from 14-16 a

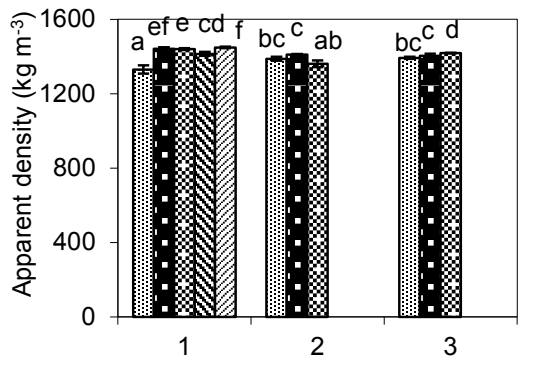

b

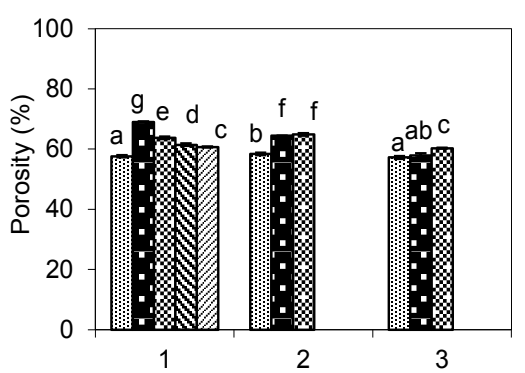

c

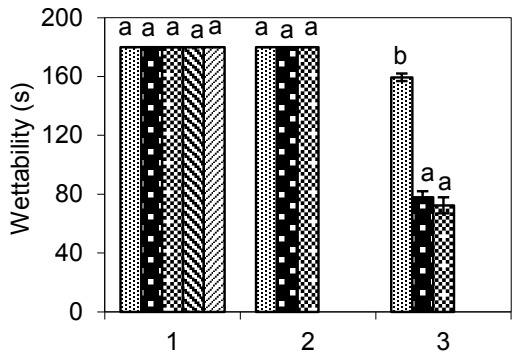

d

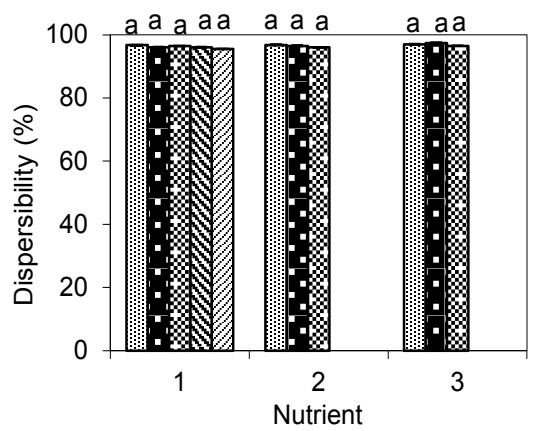

Fig. 3. Physical properties of food powders (nutrients): a - apparent density, $\mathrm{b}$ - porosity, $\mathrm{c}$ - wettability, $\mathrm{d}$ - dispersibility. Legend and explanations as on Fig. 1.

to $19-21 \%$ ), with a concurrent increase in porosity (from $57-58$ to $58-69 \%$ ) (Fig. 2c-d and 3b). This suggests considerable development of the surface of the agglomerates, which may be a cause of the increase in the Hausner ratio and Carr index values, and thus negatively influence the flowability of the studied material.

At application of water and the $15 \%$ water solution as wetting liquids, agglomeration and coating caused a significant $(\alpha=0.05)$ increase in apparent density of the nutrients, compared to the nutrients (Fig. 3a). The apparent density values for the nutrients (powdered nutrients) were in the 
range of 1330 to $1393 \mathrm{~kg} \mathrm{~m}^{-3}$, for the agglomerates obtained using water as the wetting liquid $1404-1442 \mathrm{~kg} \mathrm{~m}^{-3}$, for the agglomerates obtained using the $15 \%$ water lactose solution 1361-1440 $\mathrm{kg} \mathrm{m}^{-3}$, and for the coated agglomerates $1414-1449 \mathrm{~kg} \mathrm{~m}^{-3}$. A significant influence of the type of the wetting liquid on the differentiation of the apparent density of the particles was noted.

A significant increase in porosity of the agglomerated particle bed and selected coated agglomerates was noted, compared to the nutrients that were not subjected to these processes (Fig. 3b). The particle shape and surface properties, particle size distribution, and geometry of the system are factors affecting flowability (Dhanalakshmi and Bhattacharya, 2011). The type of the wetting liquid used in the process of agglomeration and coating significantly influenced the differences in the porosity values for the particular nutrients. The nutrients with whey protein isolate contribution (nutrients 1 and 2) agglomerated with water were characterized by higher porosity than those obtained using the water lactose solution. A reverse relationship was noted in the case of nutrient 3 , where the whey protein isolate was replaced with the soy protein isolate.

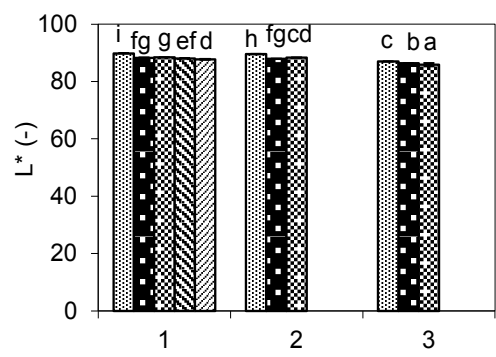

$\mathrm{b}$
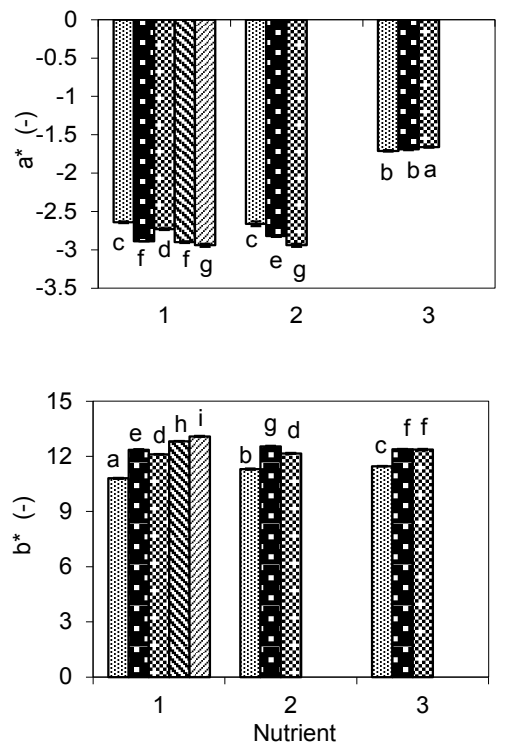

Fig. 4. Colour parameters of food powders (nutrients): $a-L^{*}, b-$ $\mathrm{a}^{*}, \mathrm{c}-\mathrm{b}^{*}$. Legend and explanations as on Fig. 1.
The application of the soy protein isolate (SPI) in the composition of nutrient 3 caused a significant decrease in the wetting time, and thus considerable improvement of wettability in comparison with the other nutrients (Fig. 3c). The addition of rice starch led to a significant increase in the viscosity of reconstituted powder and thus had an effect on the wettability (Chávez Montes et al., 2011). In turn, no significant influence on the type of the wetting liquid and coating on differentiation in the wettability of the studied nutrients in the form of powder, agglomerate, and coated agglomerate was noted.

There was no statistically significant influence of the raw material composition, the technological process used, and the type of the wetting liquid on differentiation in the dispersibility of the studied nutrients (Fig. 3d).

The agglomeration and coating with the application of water and the $15 \%$ water lactose solution as wetting liquids caused a significant $(\alpha=0.05)$ darkening of the nutrient surface (Fig. 4a). A significant influence of the type of the wetting liquid on differentiation of the brightness coefficient $\left(\mathrm{L}^{*}\right)$ of the agglomerated nutrients studied and additionally coated nutrient 1 was noted, which was probably caused by their higher water activity (Telis and MartinezNavarrete, 2010). It is possible that the Maillard reaction occurred during the agglomeration process, which is characterized by a combination of reducing sugars with aminoacids present in the food powders, under the effect of heat, resulting in darkening of the nutrient (Hiller and Lorenzen, 2010; Vissotto et al., 2010 ). The Maillard reaction is an important mode of deterioration in nutrients, which limits shelf life. It results in a decrease in quality (protein), which is accompanied by undesirable colour (browning) and functionality changes (Pereyra Gonzales et al., 2010).

The technological processes applied (agglomeration, coating) caused a significant $(\alpha=0.05)$ increase in the value of the green colour parameter $\left(\mathrm{a}^{*}\right)$ for the nutrients containing whey protein isolate (WPI) in its raw material composition (nutrients 1 and 2) (Fig. 4b). Only in the case of the agglomerate of nutrient 3 ( $25 \% \mathrm{SPI})$, a considerable decrease in the green colour was noted in comparison with the nutrient that was not subjected to agglomeration, at the application of the $15 \%$ water lactose solution.

The yellow colour parameter $\left(b^{*}\right)$ for the nutrients subected to the agglomeration process, as well as coating (nutrient 1), significantly increased, compared to the multi-component nutrients (Fig. 4c). Statistically significant differences were observed in the studied parameter depending on the type of the wetting liquid used in the agglomeration process for nutrients containing whey protein isolate (WPI) in their composition. Nutrients 1 and 2 agglomerated with water demonstrated higher contribution of yellow colour than that in the nutrients obtained at application of the $15 \%$ lactose solution as the wetting liquid. 


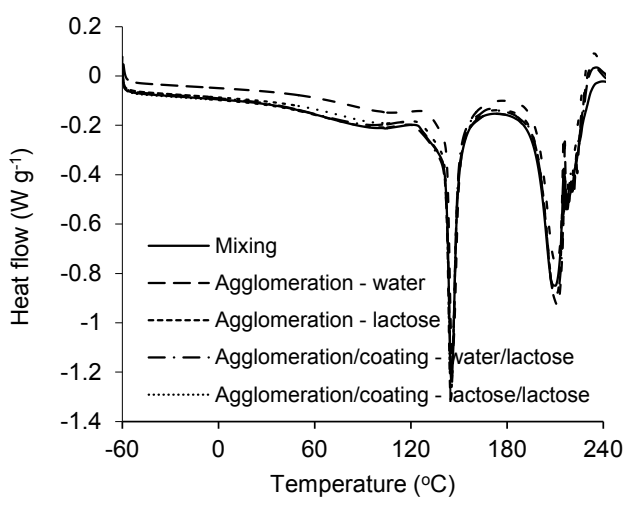

Fig. 5. Thermogram DSC of food powder - nutrient 1.

The DSC thermograms of the studied nutrients had a similar course (Fig. 5). The soft inflexion at the temperature range from about 40 to $120^{\circ} \mathrm{C}$ may be a result of surface water evaporation from the sample. The sharp endothermal peaks at the temperature of $\mathrm{ca} .144^{\circ} \mathrm{C}$ are connected with large loss of crystalline water by lactose (Chiou et al., 2008; Kaialy et al., 2011; Tang and Li, 2013). The other endothermal peaks at the temperature of $c a .211-215^{\circ} \mathrm{C}$ are the peaks for $\alpha$-lactose form melting, other 'sharped' peaks present $\beta$-lactose form melting. Similar conclusions were drawn by Ostrowska-Ligęza et al. (2012), who studied nutrients for babies with an addition of omega- 3 and omega- 6 acids. This may be influenced by other components of nutrients and agglomerates; however, lactose as a main component determines the course of all the curves. The course of the thermograms indicates that the applied technological process (mixing, agglomeration, coating) and the type of the wetting liquid (water or lactose solution) do not cause any significant changes in the physical state of the components.

\section{CONCLUSIONS}

1. The analyzed food powders were characterized by differentiated physical properties, including especially: particles size, tapped bulk density, wettability, and dispersibility. The raw material composition of the studied nutrients demonstrated a statistically significant influence on the analyzed physical properties.

2. Agglomeration and coating, irrespective of the type of the wetting liquid and raw material composition of the powdered nutrients, considerably contributed to an increase in particle size, a decrease in bulk density, an increase in apparent density and porosity of the particle bed, and deterioration of flowability, compared with the non-agglomerated nutrients.

3. Agglomeration and coating exerts a statistically significant influence on the parameters of colour of powdered nutrients: a decrease in brightness $\left(\mathrm{L}^{*}\right)$ and an increase in green $\left(-a^{*}\right)$ and yellow $\left(+b^{*}\right)$ colour, irrespective of the type of a wetting liquid used.

4. Lactose in the powdered nutrients occurs in a stable form at each stage of the technological process.

\section{REFERENCES}

A/S Niro Atomizer, Copenhagen, Denmark, 1978. Determination of wettability (Eds I. H. Sørensen, J. Krag, J. Pisecky, V. Westergaard), Analytical methods for dry milk products. Copenhagen: De ForenedeTrykkerier A/S.

Barkouti A., Turchiuli C., Carcel J.A., and Dumoulin E., 2013. Milk powder agglomerate growth and properties in fluidized bed agglomeration Dairy Sci. Technol., 93, 523-535.

Chávez Montes E., Dogan N., Nelissen R., Marabi A., Ducasse L., and Ricard G., 2011. Effects of drying and agglomeration on the dissolution of multi-component food powders. Chem. Eng. Technol., 34, 1159-1163.

Chen Y., Yang J., Mujumdar A., and Dave R., 2009. Fluidized bed film coating of cohesive Geldart group $\mathrm{C}$ powders. Powder Technol., 18, 466-480.

Chiou D., Langrish T.A.G., and Braham R., 2008. The effect of temperature on the crystallinity of lactose powders produced by spray drying. J. Food Eng., 86, 288-293.

Dacanal G.C. and Menegalli F.C., 2010. Selection of operational parameters for the production of instant soy protein isolate by pulsed fluid bed agglomeration. Powder Technol., 203, 565-573.

Dhanalakshmi S. and Bhattacharya S., 2011. Compaction agglomeration of corn starch in presence of different binders. J. Food Eng., 104, 348-355.

Domian E. and Poszytek K., 2005. Wheat flour flowability as affected by water activity, storage time and consolidation. Int. Agrophysics, 19, 119-124.

Fitzpatrick J.J., Iqbal T., Delaney C., Twomey T., and Keogh M.K., 2004. Effect of powder properties and storage conditions on the flowability of milk powders with different fat contents. J. Food Eng., 64, 435-444.

Hiller B. and Lorenzen P.C., 2010. Functional properties of milk proteins as affected by Maillard reaction induced oligomerisation. Food Res. Int., 43, 1155-1166.

Horváth Zs.H. and Hodúr C., 2007. Colour of paprika powders with different moisture content. Int. Agrophysics, 21, 67-72.

Jinapong N., Suphantharika M., and Jamnong P., 2008. Production of instant soymilk powders by ultrafiltration, spray drying and fluidized bed agglomeration. J. Food Eng., 84, 194-205.

Kaialy W., Martin G.P., Ticehurst M.D., Royall P., Mohammad M.A., Murphy J., and Nokhodchi A., 2011. Characterisation and deposition studies of recrystallised lactose from binary mixtures of ethanol/butanol for improved drug delivery from dry powder inhalers. AAPS J., 13, 30-43.

Karlsson S., Rasmuson A., Björn I.N., and Schantz S., 2011. Characterization and mathematical modelling of single fluidised particle coating. Powder Technol., 207, 245-256.

Machado V.G., Hirata T.A.M., and Menegalli F.C., 2014. Agglomeration of soy protein isolate in a pulsed fluidized bed: Experimental study and process optimization. Powder Technol., 254, 248-255.

Manickavasagan A., Thangavel K., Dev S.R.S., Aniesrani Delfiya D.S., Nambi E., Orsat V., and Raghavan G.S.V., 2015. Physicochemical characteristics of date powder produced in a pilot-scale spray sryer. Drying Technol., 33(9), 1114-1123.

Montes E.C., Dogan N., Nelissen R., Marabi A., Ducasse L., and Ricard G., 2011. Effects of drying and agglomeration on the dissolution of multi-component food powders. Chem. Eng. Technol., 34, 1159-1563. 
Ostrowska-Ligęza E., Szulc K., Wirkowska M., Górska A., and Lenart A., 2012. Influence of agglomeration and coating on oxidation stability of essential unsaturated fatty acids of powdered baby formulas (in Polish). Acta Agrophysica, 19, 77-87.

Pereyra Gonzales A.S., Naranjo G.B., Leiva G.E., and Malec L.S., 2010. Maillard reaction kinetics in milk powder: Effect of water activity at mild temperatures Int. Dairy J., 20, 40-45.

Prata A.S., Maudhuit A., Boillereaux L., and Poncelet D., 2012. Development of a control system to anticipate agglomeration in fluidised bed coating. Powder Technol., 224, 168-174.

Sharma M., Kadam D.M., Chadha S., Wilson R.A., and Gupta R.K., 2013. Influence of particle size on physical and sensory attributes of mango pulp powder. Int. Agrophys., 27, 323-328.

Shittu T.A. and Lawal M.O., 2007. Factors affecting instant properties of powdered cocoa beverages. Food Chem., 100, 91-98.

Szulc K. and Lenart A., 2010. Effect of agglomeration on flowability of baby food powders. J. Food Sci., 75, E276-E274.
Szulc K. and Lenart A., 2012. Water vapour adsorption propetries of aggwlomerated baby food powders. J. Food Eng., 109, 135-141.

Szulc K., Estkowski J., Tuwalski A., and Lenart A., 2012. Effect of water activity on flowability of infant milk powders of various raw material composition (in Polish). Acta Agrophysica, 19, 195-202.

Szulc K. and Lenart A., 2013. Surface modification of dairy powders: Effects of fluid-bed agglomeration and coating. Int. Dairy J., 33, 55-61.

Tang C.H. and Li X.R., 2013. Microencapsulation properties of soy protein isolate: Influence of preheating and/or blending with lactose. J. Food Eng., 117, 281-290.

Telis V.R.N. and Martinez-Navarrete N., 2010. Application of compression test in analysis of mechanical and colour changes in grapefruit juice powder as related to glass transition and water activity. LWT - Food Sci. Technol., 43, 744-751.

Turchiuli C., Eloualia Z., El Mansouri N., and Dumoulin E., 2005. Fluidised bed agglomeration: Agglomerates shape and end-use properties. Powder Technol., 157, 168-175.

Vissotto F.Z., Jorge L.C., Makita G.T., Rodrigues M.I., and Menegalli F.C., 2010. Influence of the process parameters and sugar granulometry on cocoa beverage powder steam agglomeration. J. Food Eng., 97, 283-291. 